\title{
O Grupo Santa Helena e o universo industrial paulista (1930-1940)
}

PATRÍCIA MARTINS SANTOS FREITAS

Mestre em História pela Universidade Estadual de Campinas (Unicamp)

\section{Resumo}

Entre as décadas de 1930 e 1940, reuniram-se em dois ateliês compartilhados no Palacete Santa Helena, os pintores que formaram o Grupo Santa Helena. Dentre suas obras, são notáveis as paisagens em que os artistas registraram o crescimento industrial e urbano de São Paulo. A presente pesquisa visa analisar este registro, por meio do estudo de obras em que os santelenistas retrataram o universo fabril e do modo como a crítica de arte do período, bem como a historiografia subseqüente, interpretaram suas produções. Objetivou-se também caracterizar as formas encontradas pelo Grupo para representar o mundo industrial em suas telas, considerando, a partir do corpus trabalhado, as paisagens industriais como aquelas em que aparecem os signos do urbano e fabril, como as chaminés das fábricas e usinas, mas também as estações de trem e a própria figura do operário.

Com intuito de compreender como o Grupo Santa Helena e suas obras se inseriram em seu momento histórico, foram estudadas suas origens, formações profissionais, além da relação que mantinham com o cenário artístico paulista da época. Para tanto, as obras santelenistas foram colocadas em diálogo com produções contemporâneas, brasileiras e internacionais, de modo a apreendermos certa sensibilidade do período. Em um segundo momento, as críticas e a historiografia foram observadas com o objetivo de se entender a construção da identidade do Grupo Santa Helena.

Palavras-chave: Grupo Santa Helena; Industrialização (São Paulo); Arte Brasileira; Patrimônio Industrial.

\section{Abstract}

Between 1930 and 1940, the painters who formed the Santa Helena Group shared a room on Palace St. Helena. Among their works are remarkable landscapes recorded by these artists of the industrial and urban growth of Sao Paulo. This goal of this research is to analyze through these works how the 
artists portrayed the factory universe and how the art critics of the period and the subsequent historiography interpreted its productions. We will also characterize which shapes the Group chose to represent the industrial world in their paintings. Also from the paintings viewed the industrial landscapes in which the signs of urban factory, as the chimneys of factories and plants, the train stations and the actual figure of the worker appears.

In order to understand how the Santa Helena Group and their works were inserted in their historical moment, we studied their backgrounds, professional qualifications, and the relationship they had with the art scene in Sao Paulo at the time. To this end, the santelenista's works were placed in dialogue with contemporary productions, Brazilian and international, in order to grasp certain sensibility of the period. In a second step, criticism and historiography were observed in order to understand the identity construction of the Santa Helena Group.

Keywords: Santa Helena Group; Industrialization (São Paulo), Brazilian Art, Industrial Heritage.

Entre meados de 1930 e 1940, um grupo de artistas que ficou conhecido como Grupo Santa Helena se reuniu em dois ateliês compartilhados no Palacete Santa Helena, no centro da cidade de São Paulo. Durante esta experiência, e por alguns anos posteriores, estes pintores registraram o crescimento urbano e industrial de São Paulo, retratando as transformações que a cidade passava na época. No registro que os santelenistas - como estes artistas ficaram conhecidos - produziram, as paisagens em que a indústria era o tema principal do Grupo existiram, mas foram menos volumosas do que o retrato que os artistas fizeram do universo industrial presente nos subúrbios de São Paulo. Isto inclui as estações de trem, gasômetros e usinas encontradas nos bairros periféricos da cidade. Com menor recorrência aparecem ainda os registros dos trabalhadores fabris, sendo encontrados apenas nas obras de alguns pintores santelenistas. Por uma questão espacial, apresento neste artigo apenas um exemplo de como os santelenistas registram a presença da fábrica nos subúrbios e como 
representaram a figura do gasômetro de São Paulo, importante edifício do século XIX.

\section{O Grupo Santa Helena: trajetórias}

O Grupo Santa Helena teve em sua formação os artistas: Aldo Bonadei (1906-1974), Francisco Rebolo Gonsales (1903-1980), Mário Zanini (19071971), Manoel Martins (1911-1979), Humberto Rosa (1908-1948), Alfredo Rullo Rizzotti (1909-1972), Clóvis Graciano (1907-1988), Alfredo Volpi (1896-1988) e Fulvio Pennacchi (1905-1992). Bonadei, Rebolo, Zanini e Manoel Martins são paulistanos, mas sua família têm origem estrangeira, como no caso de Rebolo, descendente de espanhóis e Manoel Martins, que tinha pais portugueses. Clóvis Graciano, Humberto Rosa, e Rizzotti nasceram no interior de São Paulo. Volpi nasceu em Lucca, na Itália, mas veio ao Brasil ainda quando criança. Pennacchi também nasceu na Itália, em Garfagnana, na região da Toscana, mas ao contrário de Volpi, chegou ao Brasil já adulto, em 1929. Inicio a descrição da trajetória destes até a formação do Grupo Santa Helena por Pennacchi.

Antes de chegar ao Brasil, Pennacchi havia estudado durante o ano de 1928 na Real Academia de Arte Augusto Passaglia, em Lucca, onde também lecionou por um tempo, substituindo seu mestre Antonio Pio Semeghini (18781964). Após este período, o artista passou alguns meses, entre 1929 e 1930, na Academia de Florença. Quando chegou ao território brasileiro, Pennacchi buscou empregar-se como pintor-decorador, apresentando-se em construtoras, meio em que provavelmente conheceu Mário Zanini, o qual cita no trecho escrito em seu diário na data de 08/07/1929: "... Mário se ocupou muito comigo hoje também, e talvez consiga algo na mais importante construtora daqui, a Severo e Villares ${ }^{1 \prime \prime}$. Ao mesmo tempo em que se empenhava para angariar espaço no âmbito da arte decorativa, Pennacchi administrava um açougue que comprou com o intuito de ter uma renda menos oscilante do que a que provinha da sua produção artística. Em 1936, Pennacchi expôs no III Salão Paulista de Belas

${ }^{1}$ Trecho do diário retirado do site http://www.fulviopennacchi.com. O escritório Severo e Villares, à época em que escreveu Pennacchi, acabava de perder seu fundador, o arquiteto Ramos de Azevedo e era assumido pelo também arquiteto Ricardo Severo, ao lado de Arnaldo Dumont Villares. Ramos de Azevedo fundou o escritório original, o Escritório Técnico Ramos de Azevedo em 1907 e veio a falecer em 1928. Fonte: http://www.severovillares.com.br/. Acesso em setembro de 2010. 
Artes, onde também estavam expostas obras de Volpi, Bonadei, Zanini e Rebolo, este último tendo sido apresentado a Pennacchi e assim iniciando a aproximação que o levaria aos ateliês do Palacete Santa Helena em breve.

Mário Zanini era filho de imigrantes italianos, nasceu em São Paulo e viveu quase toda sua vida na Rua Ana Neri, no Cambuci. Em frente a seu quarto de infância ficavam os paredões da fábrica Minetti-Gamba, trazendo as chaminés para seu repertório visual logo nos anos iniciais de sua vida. Em 1920, o artista estudou ainda adolescente, na Escola Profissional Masculina do Brás, a mesma em que esteve Rebolo Gonsales e Volpi². Entre 1922 e 1924, Zanini trabalhou na Companhia Antártica Paulista, confeccionando letreiros para variadas aplicações. Um ano depois, o pintor buscou aperfeiçoar seus estudos, se inscrevendo no curso de Desenho e Artes do Liceu de Artes e Ofícios de São Paulo, onde se formou em 1926. Em 1933, o pintor Paschoal Graciano recomendou Zanini a Rebolo e novamente o metiê os aproximou. Assim, em 1934, Zanini passou a trabalhar junto de Rebolo, no escritório de decoração montado no Palacete Santa Helena, onde recebiam as encomendas de empreiteiros e caiadores.

Nascido em Lucca, na Itália, Volpi veio ao Brasil com sua família aos dois anos de idade. Ainda na infância, o artista estudou na Escola Masculina do Brás e este é o último registro de instituição de ensino encontrado na biografia de Volpi. O próprio pintor se considerava autodidata ${ }^{3}$ e não há pistas de passagens de Volpi por nenhuma escola de arte no período. Após o fim dos estudos básicos, em 1911, o artista começou a trabalhar como marceneiro, entalhador e encadernador. Mantendo-se próximo dos trabalhos de decoração, Volpi tomou contato com Zanini e Rebolo, e assim passou a freqüentar os ateliês no Palacete Santa Helena na década de 1930. Contudo, a fama como artista ganhou força na

${ }^{2}$ A Escola Masculina do Brás, assim como o Liceu de Artes e Ofícios, foi uma iniciativa estadual para dar conta da educação do contingente populacional que aumentava com a industrialização de São Paulo, e com o grande número de imigrantes que chegavam à cidade no período. Chamada também de Escola Técnica Estadual Getúlio Vargas, foi criada em 1911 e era dedicada ao ensino infantil e adulto. Era uma escola especializada em Artes e Ofícios e tinha como objetivo a incorporação das classes menos abastadas ao mercado de trabalho crescente.Fonte:http://www.itaucultural.org.br/aplicexternas/enciclopedia_ic/index.cfm?f useaction $=$ instituicoes_texto\&cd_verbete $=5397 \& c d \_i t e m=12$. Acesso em setembro de 2010.

3 Depoimento prestado a Walter Zanini, em maio de 1976, reproduzido em ZANINI, Walter. A arte no Brasil nas décadas de 1930-40: O Grupo Santa Helena. São Paulo: Nobel, 1991. p. 125. 
década de 1940, quando Volpi venceu um concurso do Instituto do Patrimônio Histórico e Artístico Nacional com trabalhos realizados com base nos monumentos das cidades de São Miguel e Embu, em São Paulo. Em 1944, o artista fez sua primeira exposição individual em São Paulo e em 1950 viajou com Zanini e Paulo Rossi Osir para a Europa. Três anos depois, o reconhecimento de seu trabalho artístico veio com o prêmio de Melhor Pintor Nacional da Bienal de São Paulo, o qual dividiu com o pintor Di Cavalcante (1897-1976).

Aldo Bonadei teve trajetória diversa da maior parte do Grupo, indo ao exterior para estudar arte antes de se unir ao outros artistas do Grupo Santa Helena. Bonadei morava em Santos, litoral paulista, e veio a São Paulo em 1923 para ter aulas de desenho e composição com Pedro Alexandrino (1730-1812) e Antonio Rocco (1880-1944), sendo ambos também professores do Liceu de Artes e Ofícios. Em 1925, Bonadei estudou no próprio Liceu, o curso noturno de Desenho, no qual provavelmente conheceu Mário Zanini. Em 1930, o artista conseguiu fixar-se em Florença, na Itália, onde freqüentou a Academia de Belas Artes, a mesma que Pennacchi, contudo, um ano após a vinda deste para o Brasil. Em 1931, Bonadei voltou ao Brasil. Antes da sua entrada no Grupo, o pintor já expunha em salões oficias (Salão Paulista de Belas Artes, Salões de Maio I e II, Salão Nacional de Belas Artes do Rio de Janeiro, dentre outros). Nestes salões, Bonadei tomou contato com Rebolo e assim se aproximou dos outros pintores, indo também dividir o aluguel do ateliê situado no Palacete.

Manoel Martins morou ao longo da infância no bairro do Brás, juntamente com sua família de origem portuguesa. Seu primeiro ofício, ligado à ourivesaria, veio por volta de 1924. Alguns anos depois, o artista passou a se dedicar a relojoaria e trabalhou ainda no comércio. Em 1931, conseguiu estudar com o escultor Vicente Larocca (1862-1964), que o indicou os estudos de desenho com modelo vivo, na Sociedade Paulista de Belas Artes, onde Martins efetivamente estudou em 1935. Neste ambiente conheceu Rebolo e Zanini e assim se instalou, ainda em 1935, no Palacete Santa Helena. Dois anos depois, Martins expôs junto aos outros artistas que freqüentavam o Palacete na I Exposição da Família

\footnotetext{
${ }^{4}$ Pedro Alexandrino foi discípulo de Almeida Jr. e aluno da Academia de Belas Artes. O artista também trabalhou na França sob a orientação de Volton e Chrétien. No Brasil, foi professor de desenho de figura e paisagem, no Liceu de Artes e Ofícios. Para mais informações, ver: GONÇALVES, Lisbeth Rebollo. Aldo Bonadei: o percurso de um pintor. São Paulo: Perspectiva, 1990.
} 
Artística Paulista, afirmando no cenário artístico paulistano sua afinidade com os membros do Grupo Santa Helena.

Clóvis Graciano nasceu em Araras, interior de São Paulo, e ainda criança ajudava na oficina de sua família, decorando com pintura a óleo carroças e charretes. Com 20 anos, Graciano empregou-se na Companhia Ferroviária Sorocabana, fazendo os letreiros e avisos para as estações de trem. Em 1932, por ocasião da Revolução Constitucionalista, Graciano, que foi o único artista dentre os santelenistas que mantinha contato com o Partido Comunista, foi preso e enviado ao Rio de Janeiro. Depois de solto, o artista voltou para São Paulo, onde conheceu Cândido Portinari (1903-1962) e passou a freqüentar o curso de desenho com modelo vivo na Sociedade Paulista de Belas Artes, um ano antes de Martins o ter feito, em 1934. Entre 1936 e 1937, conviveu com o pintor modernista Waldemar da Costa (1904-1982) em seu ateliê. Neste mesmo período, passou a freqüentar por dois ou três anos as salas do Palacete Santa Helena, entrando no lugar de Bonadei, que deixava de dividir o aluguel com os outros santelenistas.

Em Santa Cruz das Posses, interior de São Paulo, Humberto Rosa começou a trabalhar cedo, ajudando o pai no armazém da família, oriunda da Itália. Rosa chegou à capital de São Paulo em 1927 para estudar na Escola Paulista de Belas Artes, de onde saiu em 1932. Neste meio tempo, conheceu Rebolo, o qual, por volta de 1936, o levou para compartilhar o ateliê no Palacete Santa Helena. Já unido aos santelenistas, Rosa lecionou Desenho, assim como Pennacchi, no Colégio Dante Alighieri, e também no Colégio Bandeirantes e Sion. Sua saúde era fragilizada, e deste modo, participou apenas de algumas exposições junto ao Grupo Santa Helena, falecendo no final da década de 1940.

Alfredo Rullo Rizotti foi o último artista a inserir-se no Palacete Santa Helena, já em 1937. Rizzotti, assim como Bonadei, pôde ir ao exterior para estudar artes antes de unir-se aos santelenistas. Com 15 anos de idade, Rizzotti foi à Itália, só voltando em 1935, na altura de seus 26 anos. Lá estudou na Escola Profissional Novaresca e na Academia Albertina de Turim, como aluno livre. De volta ao Brasil, exerceu as atividades de torneiro mecânico, mecânico de automóveis e fresador. Assim como Humberto Rosa, Rizzotti tinha sérios problemas de saúde, os quais incluíam alergia às tintas, dificultando seu trabalho 
nas artes plásticas. A despeito disso, o artista permaneceu expondo ao lado dos santelenistas em diversas ocasiões, dentre as quais no Salão Nacional de Belas Artes e no Salão Paulista de Arte Moderna, sendo premiado com medalhas de prata e bronze, na década de 1940.

Francisco Rebolo Gonsales foi uma figura central para o Grupo Santa Helena, pois aglutinou os outros membros, sempre estando próximo a todos e permanecendo no Palacete Santa Helena até $1952^{5}$. Filho de imigrantes espanhóis, fez seus estudos no Grupo Escola da Mooca, mas por necessidades financeiras, precisou começar a trabalhar muito cedo, e já na adolescência atuou como entregador de chapéus e iniciou-se como aprendiz de pintor, com auxílio de seu irmão mais velho. Durante este período, decorou muitas residências, bem como detalhes das Igrejas de Santa Ifigênia e Santa Cecília. Rebolo morou no Brás e freqüentou a Escola Profissional Masculina do Brás. Entre 1917 e 1934, o pintor atuou como jogador de futebol profissional, em vários times, dentre eles o Corinthians Paulista, o Clube Atlético Ipiranga e a Associação Atlética São Bento. Mesmo durante este período, Rebolo não deixou de exercer seu ofício, e assim se aproximou cada vez mais de Zanini, Volpi e dos outros pintores que formariam o Grupo Santa Helena. Em 1926, o artista montou seu ateliê na Rua São Bento para estudar pintura e, sobretudo, receber encomendas de decoração. A partir de 1933, Rebolo transferiu seu escritório/ateliê para as salas do Palacete Santa Helena. Assim como outros santelenistas, o artista viajou para a Europa em 1955, em decorrência do prêmio recebido no $3^{\circ}$ Salão Nacional de Arte Moderna ${ }^{6}$.

O Grupo Santa Helena expôs em conjunto apenas em 1966, muitos anos após a dissolução dos ateliês no Palacete. Na década de 1970, três novas exposições aconteceram em São Paulo. Em 1973 e 1975, sob curadoria de Lisbeth Rebollo Gonçalves e em 1977, sob a curadoria de Daisy Peccinini. Em 1981, ocorreu na Dan Galeria, em São Paulo, a exposição "Rebolo e os Pintores

${ }^{5}$ Rebolo, no entanto, não foi o último a deixar o Palacete. Mário Zanini, que deixou o ateliê do Palacete por alguns anos, em que esteve associado a Raphael Galvez, Joaquim Lopes Figueira e Mário Levy, voltou ao Palacete em 1940, saindo por definitivo apenas em 1965. O Palacete Santa Helena foi demolido em 1971, ano da morte de Mário Zanini. Fonte: ZANINI, Walter. A arte no Brasil nas décadas de 1930-40: O Grupo Santa Helena. São Paulo: Nobel, 1991.

6 CAMPOS, Celia Lucia Rodrigues Torres Parahyba. Rebolo: uma poética da paisagem. São Paulo: Universidade São Paulo, 1990, 159p. (Dissertação, Mestrado em Artes). 
do Grupo Santa Helena". Marcando 30 anos da união do Grupo, foi a vez de Walter Zanini e Marília Saboya de Albuquerque serem curadores da mostra no Museu de Arte Moderna de São Paulo. Em 2000, mais uma exposição contemplou o Grupo na Galeria Jô Slavieiro. Por fim, em 2002, a então diretora do Museu de Arte Contemporânea, Elza Ajzemberg, em parceria com o SESI (Serviço Social da Indústria), reuniu novamente os santelenistas na exposição "Operários na Paulista"7. Ademais, os santelenistas participaram de diversos salões juntamente com artistas modernistas nas décadas de 1930 e 1940, e também em exposições individuais, sobretudo a partir de fins de 1940 e 1950.

\section{Paisagens do subúrbio: espaços de fronteira}

O subúrbio foi um dos temas mais explorado pelas paisagens do Grupo Santa Helena. Nestas paisagens podemos encontrar a representação de diversos bairros de São Paulo que estavam se espraiando ao redor da parte central da cidade. O estudo das paisagens suburbanas pintadas pelo Grupo revela a escolha pelo recorte do ambiente ainda rural, mas que já apresentava signos modernos como, por exemplo, as fábricas. As obras refletem um espaço intermediário entre a paisagem urbana e a paisagem industrial. Os bairros periféricos eram os novos abrigos para a incipiente industrialização. Contudo, ainda mantinham reminiscências de um mundo fortemente ligado às tradições rurais. Os arredores de São Paulo eram os lugares que mais fortemente denunciavam as mudanças pelas quais a cidade passava. Neste ambiente conviviam as duas medidas que davam ritmo a vida paulistana. Este era o espaço de coexistência entre a modernidade e a tradição.

A prática da pintura ao ar livre levava os pintores e seus instrumentos aos arrabaldes de São Paulo, em jornadas dominicais, em grupos ou individualmente. Para este deslocamento, contribuiu efetivamente a acessibilidades que os subúrbios tinham através de transportes baratos como os trens ${ }^{8}$. Como grandes observadores do cotidiano da cidade, os membros do Grupo retratavam a

7 COSTA, Helouise. A exposição como tema: o exemplo do Grupo Santa Helena. In: "Operários na Paulista: MAC USP e Artistas Artesãos". Elza Ajzemberg (org.). São Paulo: MAC USP, 2002.

8 As linhas de trem têm papel importante tanto no transporte dos membros do Grupo Santa Helena, como na inspiração para temas pintados pelo Grupo. 
industrialização de São Paulo, o crescimento dos bairros e também o lazer de final de semana. A conversa no portão, as pessoas caminhando e as figuras comuns têm ao fundo, eventualmente, a paisagem urbana, a fábrica, ou a silhueta de uma chaminé. São crianças, ciclistas, pais e filhos que caminham de mãos dadas, em um passeio na periferia de São Paulo. A artista Alice Brill, a qual conviveu e fotografou tanto o Grupo Santa Helena, como a cidade de São Paulo durante as décadas de 1930 e 1940, assim descreveu a prática dos artistas:

Aos domingos, os amigos iam para a periferia da cidade, como o Canindé, ao longo do rio Tietê com suas pontes e lavadeiras, ou ainda para o interior ou litoral próximos, para pintar ao ar livre (BRILL, 1986).

O adentramento da indústria na periferia de São Paulo ressignificou este espaço e provocou impacto visual registrado por fotógrafos, artistas, literatos e intelectuais diversos. A imagem foi a linguagem escolhida pelo Grupo Santa Helena para a expressão de sua sensibilidade quanto às mudanças ocorridas na cidade. Contudo, outras linguagens foram usadas por aqueles que pensaram a cidade como forma de sentir e expressar suas impressões das novas paisagens paulistas. A modernidade era um tema em voga. O jornalista Ernani Silva Bruno relatou em suas memórias de 1925, ano em que chegou a São Paulo, como se desenhavam algumas paisagens da cidade, que certamente poderiam ser tema de um quadro santelenista:

(...) para os lados do Brás, do Belém, da Mooca, estendiamse imensos quarteirões de pequenas casas geminadas, em ruas sem pavimentação e sem árvores, alternando às vezes com grandes edifícios de tijolo aparente ou de paredes de um encardido cinzento de fuligem à sombra de altas chaminés que tentavam enfumaçar o céu (BRUNO, 1986, p. 49-51).

Para os santelenistas, a fábrica dentro dos subúrbios não é tema central e, a despeito de aparecer com freqüência em suas paisagens dos arredores da capital paulista, o que se pode observar a partir de um olhar geral nas obras do Grupo é um tratamento lírico que valoriza a presença fabril como parte integrante do cenário suburbano. Um exemplo desta abordagem da paisagem dos arrabaldes é a obra Sem título (Canindé), de Mário Zanini, feita em 1942 [fig. 02]. O singelo pescador, com seu chapéu e sua vara, chama atenção no 
primeiro plano do quadro. À sua esquerda, duas pessoas carregam sacos na cabeça. Com um lenço branco enrolado na cabeça, se aproxima uma mulher, a caminhar pela margem do rio. Estas figuras, dispostas nos planos mais próximos do espectador, emolduram as três casas que aparecem ao fundo. São três casebres e uma pequena fábrica, dotada de uma chaminé fumegante, além de três altos postes exibindo seus fios pelo céu predominantemente cinza, com pinceladas de azul.

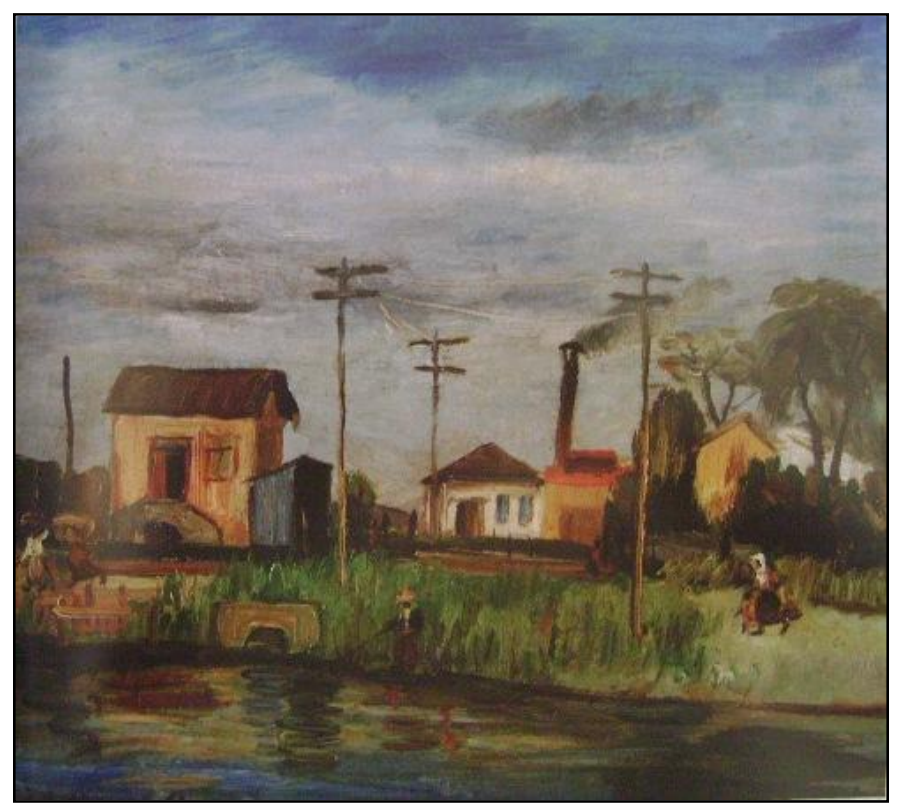

Figura 02: Mário Zanini, Sem título (Canindé), 1942. Óleo sobre tela, 35,3 x $40 \mathrm{~cm}$. Coleção Orandi Momesso. 
Inserido no distrito do Pari, situado na região central de São Paulo, o bairro do Canindé se localiza entre os rios Tamanduateí e Tietê. Como aponta o pescador de Mário Zanini, a pesca era uma prática usual nestes rios, que por muitos anos funcionaram como meio de sustento das primeiras famílias a se instalarem no Pari, no século XVI. Muitos anos depois, já nas primeiras décadas do século XX o Canindé se consagrou como o "bairro doce". O apelido veio com as fábricas de doces que se espalharam pelo local, enfeitiçando a atmosfera do bairro com o aroma adocicado de sua produção. O grande número de imigrantes a desembarcar no porto de Santos - portugueses, japoneses, e italianos, entre outros - logo ocupou os bairros de São Paulo. As fábricas, vilas operárias, e mesmo as ruas, do Brás, Barra Funda, Pari, para mencionar apenas alguns lugarejos, se encontravam cheias de estrangeiros. A fábrica retratada por Zanini, em 1942, pode ser uma destas indústrias de doces, mais especificamente a fábrica de biscoitos Bella Vista, a qual se situava próximo ao rio Tietê, formando assim um cenário semelhante ao retratado pelo pintor. Juntamente com a fábrica Bella Vista, havia outras fábricas, como a Fábrica Dizioli, a Confiança e a Neuza, todas especializadas no ramo de doces e biscoitos. Contudo, os indícios pesquisados e aqui apresentados são insuficientes para identificar com precisão qual fábrica Zanini representou.

$O$ retrato de Zanini alude à tranqüilidade de um bairro, onde se podia brincar na rua, comer doces, pescar e andar de bicicleta. Mesmo a fumaça negra que sai da chaminé no centro do quadro aparentemente não aborrece esta dinâmica. E a cena parece prosseguir alheia à presença do pintor. Como aponta a historiadora da arte Daisy Peccinini, Zanini tinha afeição em representar "(...) os bairros proletários, ruas e casas humildes, onde o povo se movimenta nas ruas e nas várzeas onde trabalha e se diverte (PECCININI, 2007, p. 20)". A fábrica na obra de Zanini funciona como um elemento de estruturação da cena, indicando a convivência entre os elementos que caracterizam o universo do trabalho e do descanso. Embora Zanini se preocupe em legitimar sua cena com a presença da indústria, esta aparece ao fundo, em terceiro plano, precedida em segundo plano pela casa suburbana, característica nas obras dos santelenistas, e em primeiro 
plano pelas figuras humanas ${ }^{9}$. A chaminé fumegante não está isolada e partilha com os postes de eletricidade representados a função de trazer verticalidade para a paisagem pintada, além de personificar os signos da modernidade no ambiente rural.

\section{Paisagens Industriais}

Enquanto os anos de 1930 e 1940 foram repletos de paisagens santelenistas do subúrbio, nas quais freqüentemente a fábrica aparece em plano secundário, a partir de meados da década de 1940, para muitos pintores que expuseram com o Grupo Santa Helena, como Raphael Galvez e Joaquim Figueira, e da década de 1950, para alguns dos santelenistas, a paisagem industrial entendida como paisagem que representa a indústria como objeto central passou a aparecer com maior freqüência. Os artistas cujas obras representaram as indústrias com maior evidência são: Mário Zanini, o qual pintou de maneira mais assídua as indústrias de São Paulo, que já apareciam, como visto, em seus retratos do subúrbio e Francisco Rebolo Gonsales, que, após Zanini, foi o artista que mais representou em suas obras aspectos do mundo industrial, incluindo muitas vezes não apenas a paisagem industrial, mas também a figura do trabalhador. Clóvis Graciano, Fulvio Pennacchi e Aldo Bonadei também registraram a indústria, embora com menor destaque que Zanini e Rebolo. Não encontrei registros de paisagens industriais em Volpi, Humberto Rosa e Alfredo Rizzotti, para além dos panoramas dos arredores da cidade, que incluíam as fábricas ao fundo.

O aumento da freqüência das paisagens que envolvem a indústria como tema central nas obras santelenistas coincidiu com a entrada das tendências abstracionistas no Brasil. O expoente mais significativo deste período foi a realização da I Bienal Internacional de Arte, realizada em São Paulo, no ano de 1951. Os santelenistas, como tantos outros artistas do período, foram, de algum modo, impactados pelo ideal abstracionista e pela modernidade radical encontrada nas formas puras e geometrizadas. Os reflexos disso podem ser

\footnotetext{
${ }^{9}$ Ao olharmos as obras de Mário Zanini que representam as indústrias, podemos notar que a presença humana é uma constante. Sempre em primeiro plano, a figura humana assume as funções de escala para a paisagem que se ergue ao fundo, bem como traz uma dimensão de veracidade para a cena retratada.
} 
observados em algumas pinturas do Grupo Santa Helena, nas quais, sem abrir mão da figuração, estes artistas pintaram paisagens industriais geometrizadas. Dentre os pintores que mais se aproximaram desta nova linguagem, estão Volpi, Zanini, Rebolo e Bonadei ${ }^{10}$.

Em 1957, Arcângelo Ianelli ${ }^{11}$ pintou Bairro Fabril, obra em que o artista descreveu uma construção fabril de um ponto de vista bem específico [fig. 03]. Como se vendo o edifício na esquina de uma rua, da calçada oposta, Ianelli recortou a paisagem, de modo que a fábrica representada extrapola as dimensões do quadro e o observador fica privado da visão geral do conjunto arquitetônico. Quase uma década depois, Mário Zanini parece voltar ao mesmo ponto que Ianelli e pintar Fábrica, de 1966 [fig. 04]. A pequena faixa de rua que aparece em ambos os quadros no primeiro plano revela o ponto de vista do pintor, que pinta a paisagem logo a sua frente, tendo como local de partida a rua que está bem abaixo de seus pés, no seu campo de visão. Estas paisagens industriais diferem substancialmente das paisagens suburbanas santelenistas, em que a indústria aparece nuançada, em uma vista que está fisicamente distante do ponto onde o pintor se localiza. As indústrias retratadas por Zanini e Ianelli adquirem caráter monumental, sobretudo em Fábrica, obra na qual as pessoas retratadas transitando em frente à construção fabril funcionam como escala, denotando a grandeza da máquina representada.

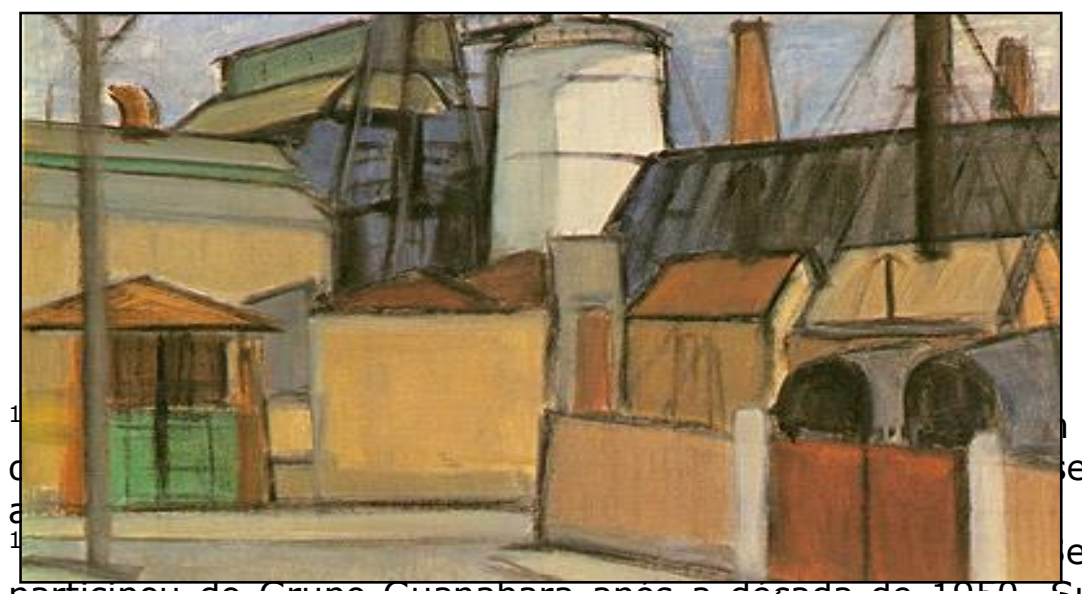

pelo abstracionismo, como é e "das bandeirinhas", do que

eibi dentre 1930 e 1940, e Figura 03: Arcângelo Ianelli, Bairro Fabril, 1957. Óleo sobre tela, 46 x Juas mostras coletivas foram $\mathrm{t}_{60 \mathrm{~cm}}$. Colecão não informada. ram dos santelenistas. Desta forma, a conexao entre os artıstas que rormaram os aoıs grupos foi se fortalecendo, seja no convívio pessoal, seia nos escritos de intelectuais como Pawlo Mendes de Almeida. Tal crítica aproximou Iane subúrbios, a qual, em figuras industriais que

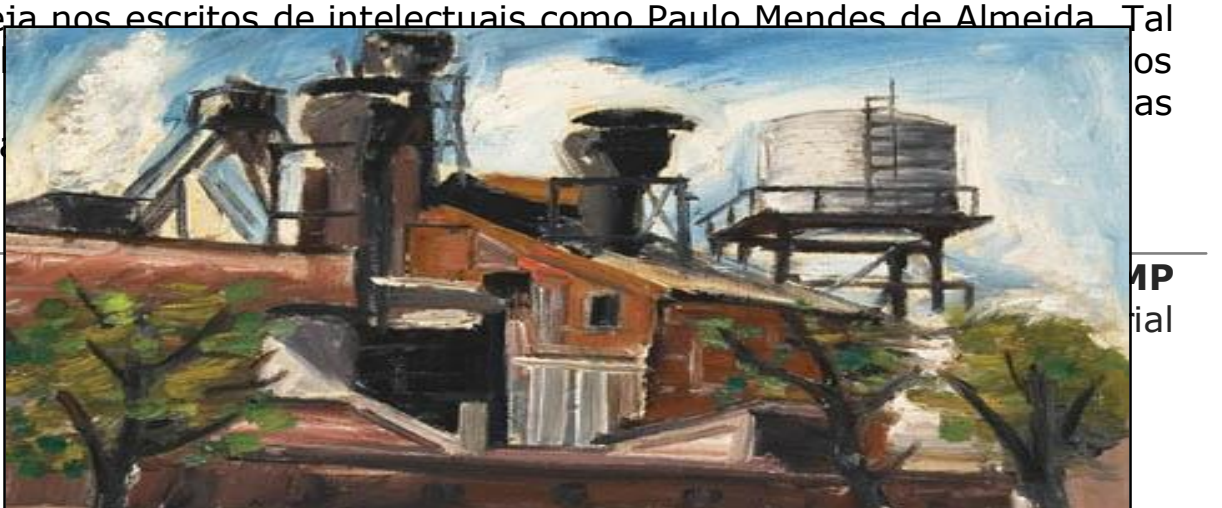


A obra Gasômetro de São Paulo, pintada em 1969 por Zanini [fig. 05], guarda semelhanças notáveis com Fábrica [fig. 04]. Lado a lado, as duas obras nos permitem intuir ser o mesmo local representado em ambas, à exceção da caixa d'água, que não aparece no quadro de 1969. As torres e o edifício têm o mesmo formato e ocupam a mesma posição em ambas as telas. Com a pintura Gasômetro de São Paulo, Zanini nos informa muito sobre a obra feita três anos antes. O que era uma fábrica genérica passa a ter um endereço.

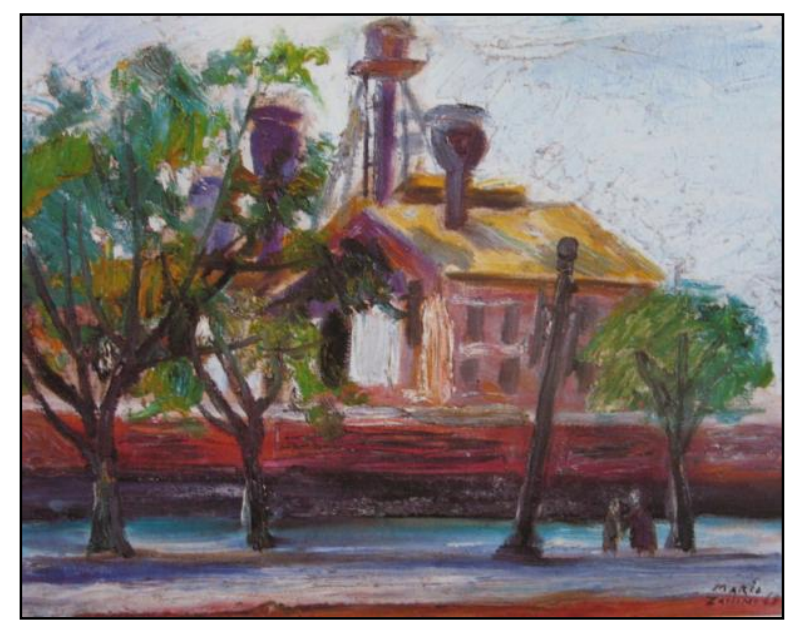

Figura 05: Mário Zanini, Gasômetro de São Paulo, 1969. Óleo sobre tela, 36 x $46 \mathrm{~cm}$. Coleção Simão Mendel Guss.

O gasômetro de São Paulo representado por Zanini foi inaugurado em 1890 e foi desativado em 1974. Situado na várzea do Tamanduateí, e construído pela empresa inglesa The San Paulo Gas Company, sua arquitetura é herdeira do estilo industrial inglês, com tijolos vermelhos e estruturas, como os balões de armazenamento do gás, trazidas diretamente da Inglaterra, entre os anos de 1898 e 1908. Ainda no século XIX, o gasômetro armazenava e distribuía o gás por meio da queima da hulha - uma espécie de carvão vegetal, formado a partir de folhas, galhos e raízes de árvores decompostas em pântanos - que vinha de navio, do Reino Unido para São Paulo. Na época, o gás era utilizado na iluminação pública, que contava com 700 lampiões, e em aquecedores e fogões domésticos nas apenas 174 residências cadastradas para receber o benefício. Nas primeiras décadas do século $X X$, os lampiões da cidade cresceram e saltaram da casa das centenas para os milhares de postes espalhados pelos bairros em 
franco desenvolvimento. O avanço econômico e tecnológico de São Paulo na década de 1930, impulsionado pelo aumento do aparato industrial na cidade, auxiliou a substituição da iluminação pública a gás pela elétrica, em meados da década. Este fato foi registrado por Zanini, em obras as quais os postes de eletricidade aparecem conduzindo fios elétricos, sobretudo nas paisagens suburbanas, como em Sem título (Canindé) [fig. 02]. No final da década de 1960, época em que Zanini retratou a usina de gás, o edifício foi desapropriado pela Prefeitura de São Paulo, que passou a ser responsável pelo serviço de distribuição. Após a sua desativação, o gasômetro ficou abandonado até 2006, quando o Condephaat (Conselho de Defesa do Patrimônio Histórico, Arqueológico, Artístico e Turístico do Estado de São Paulo) tombou o complexo do gasômetro e as obras de restauro começaram. Atualmente a usina fica aberta à visitação do público e abriga a área de operações, almoxarifado e o laboratório da Comgás (Companhia de Gás de São Paulo, que detém a concessão para distribuição de gás na cidade desde 1999), bem como um museu com exposição permanente sobre a história do gás.

Entre Fábrica, de Zanini - vista então como retrato do gasômetro de São Paulo - e Bairro Fabril, de Ianelli, podemos encontrar um ponto em comum, a saber, a caixa d'água branca, que pode representar o elo entre as duas paisagens industriais. Ianelli nos aponta como existiam outros artistas em São Paulo, além dos santelenistas, que viam o universo fabril como tema pictórico. Em sua suposta descrição da usina de gás da cidade, o artista tem uma visão menos panorâmica que Zanini, mas assim como o santelenista, atribui cores que vão do bege ao marrom à arquitetura fabril que, sabemos, invocava estes tons através de seus tijolos vermelhos manchados pela fuligem. As cores cinza e preto também marcam presença em ambas as obras, desta vez não nas nuvens, como nos registros do subúrbio santelenista, mas nos telhados, nas ruas e nas estruturas metálicas. O verde que antes era explorado em suas nuances na natureza dos arredores de São Paulo, agora aparece como uma nota nas árvores de Zanini, ou no portão de uma casa, em Ianelli. A paisagem representada se tornou urbana e industrial por completo. A natureza, que ainda ocupava boa parte dos bairros periféricos da cidade, nestas telas fora subjugada pelo ferro, aço e tijolos das usinas, gasômetros e fábricas. 
De certo modo, o ambiente do trem e da paisagem industrial se tornou familiar aos santelenistas. Todo este cenário foi representado pelo Grupo Santa Helena como o registro de alguém que estava inserido neste espaço tão naturalmente que sua presença não seria ponto de perturbação. Entretanto, isso não significa afirmar que os membros do Grupo Santa Helena, de alguma forma, se identificavam diretamente com os espaços retratados, como alguns críticos do período asseguraram. Nem tampouco, o conjunto de suas obras pode nos indicar que este era um tema de constante reflexão para os santelenistas, haja vista que o universo industrial e, mais ainda a figura dos trabalhadores, são bem menos numerosos que as paisagens suburbanas, por exemplo. Mesmo ao retratar a indústria, a preocupação dos artistas do Grupo Santa Helena pareceu repousar na plasticidade das formas e cores, muito mais do que em aspectos concernentes ao conteúdo social dos quadros.

É possível compreender os santelenistas e sua relação com as dimensões industriais de São Paulo, a partir de duas formas de aproximação entre o Grupo Santa Helena e o mundo fabril paulistano. Podemos, assim, entender estes artistas como observadores e retratistas deste universo, e/ou como membros deste mundo. Para certas correntes historiográficas, os níveis em que os santelenistas estiveram próximos da fábrica determinaram sua escolha pictórica pela paisagem industrial e suburbana em detrimento de outros temas de pintura. Entretanto, é preciso ressaltar que o processo de conexão entre o pertencimento às classes operárias e a sensibilidade artística dos santelenistas foi o produto de uma construção complexa ao longo das décadas de 1930 e 1940, empreendida, sobretudo, pela crítica de arte da época.

À medida que os santelenistas ganhavam cada vez mais espaço nos salões de artes, os críticos aumentavam a freqüência e o volume de notas sobre os pintores do Palacete. Os artigos tinham a importante função de divulgar os salões de arte moderna, que contavam com novas contribuições dos santelenistas. Enquanto faziam a propaganda do Grupo, os intelectuais forneciam sua reconhecida opinião sobre os artistas que debutavam no cenário artístico paulista. Desta forma, em pouco tempo os pintores ganharam um destaque que seria fundamental para a carreira futura destes, bem como para a formação de sua identidade. O que notamos com muita freqüência é que nos artigos em que 
os membros do Grupo Santa Helena estão em destaque, existe constantemente um referencial oculto. Este referencial é o ponto de orientação para os críticos e aquele com o qual os santelenistas serão recorrentemente comparados, inclusive no que diz respeito à representação da cidade: os modernistas da Semana de 1922.

No esforço de historicizar o Grupo Santa Helena e sua relação com o universo industrial, busquei outros pontos de contato com o cenário artístico paulista. Embora compreenda o importante papel dos artistas da Semana de 1922, acredito que existem outros grupos de artistas que nos informem muito mais sobre a realidade dos santelenistas, como por exemplo, o Grupo Seibi, do qual estavam próximos artistas como Arcângelo Ianelli. Ao contrário dos artigos de Mário de Andrade, por exemplo, que nos permitem obter mais evidências de sua filosofia do que dos santelenistas, as paisagens de Ianelli, quando posta em diálogo com obras do Grupo, nos trazem dimensões sobre a vivência que estes grupos tinham em comum com a cidade. O objetivo, desta forma, não seria buscar a apreensão das paisagens santelenistas por meio de seus antônimos, mas de seus semelhantes em meio aos grupos de artistas na São Paulo dos decênios de 1930 a 1970.

Qual é então o universo industrial paulista compreendido pelo Grupo Santa Helena? Que lugares ocupam as fábricas, as usinas, os gasômetros, as estações de trem e os trabalhadores urbanos na apreensão dos santelenistas? O universo industrial que nos é apresentado pelos santelenistas é um mundo de apreensão visual, muitas vezes verossímil e destituído de figuras alegóricas. No caminho de bonde entre suas casas e o Palacete Santa Helena, na vista dos ateliês no centro de São Paulo, no passeio até os arredores da cidade, nas redondezas dos bairros onde moravam,ou ainda no trajeto que percorriam a pé entre um Café e uma exposição de arte. Lá estavam as paisagens industriais com as quais se ocuparam os pintores do Grupo Santa Helena. O tema estava no recorte que o olhar fazia do cotidiano, nos caminhos entre a cidade e o subúrbio, na convivência diária que os artistas mantinham com a cidade. Contudo, diferentemente dos impressionistas, que saíam a observar a cidade e expressá-la em estudos de luz e atmosfera, as pinturas santelenistas revelam um apreço 
pelo desenho e pela estrutura, além de um uso diversificado da paleta, explorando desde as cores fauvistas até cores mais sóbrias e econômicas.

O tema do crescimento industrial e urbano de São Paulo aparecia na literatura, nas fotografias, nos escritos de especialistas como engenheiros, sanitaristas e médicos. Nos artistas do Grupo Santa Helena, a indústria parece ter ganhado cada vez mais a atenção dos artistas ao longo dos anos. O primeiro contato se deu nos arrabaldes da cidade, aparecendo ao fundo de um cenário ainda ruralizado, na fronteira entre o campo e a cidade. Aos poucos, o retrato da paisagem ganhou um desenho geometrizado, o que de certo modo levou alguns pintores a focalizar mais a arquitetura fabril em detrimento de outros objetos. As vistas dos ateliês alugados no centro de São Paulo também mostram a proximidade da indústria, na figura de uma chaminé ou de um edifício fabril retratado na paisagem em que o olhar alcança, a partir das janelas do Palacete Santa Helena.

O retrato das indústrias de São Paulo feito pelos santelenistas não tinha o objetivo de ser o registro histórico destas paisagens, mas acabou por fazê-lo. Algumas paisagens pintadas pelo Grupo Santa Helena mostram lugares ermos que foram rapidamente engolidos pelo crescimento urbano. Fábricas como a retratada por Raphael Galvez em Fábrica de Cimento Perus definham à espera de resoluções e mesmo o Palacete Santa Helena encontrou seu fim na dinâmica destrói/constrói que sempre marcou a história da capital paulista. O Grupo Santa Helena e suas paisagens suburbanas, urbanas e industriais não são apenas o registro de uma cidade do passado, mas a memória de vivências na cidade para as quais não temos mais acesso.

\section{Bibliografia}

ALMEIDA, Paulo Mendes de. De Anita ao Museu. São Paulo: Perspectiva, 1976.

BRILL, Alice Czapsky. Aspectos da obra de Mário Zanini: do Grupo Santa Helena às Bienais. São Paulo: USP, 1982 (Dissertação de Mestrado em Filosofia).

CAMPOS, Celia Lucia Rodrigues Torres Parahyba. Rebolo: uma poética da paisagem. São Paulo: Universidade São Paulo, 1990, 159p. (Dissertação, Mestrado em Artes). 
CAMPOS, Candido Malta (org.). Palacete Santa Helena: um pioneiro da modernidade em São Paulo. Editora Senac São Paulo: São Paulo, 2006.

GONÇALVES, Lisbeth Rebollo. Aldo Bonadei: o percurso de um pintor. São Paulo: Perspectiva, 1990.

LÉVI-STRAUSS, Claude. Saudades de São Paulo. Tradução Paulo Neves. Ricardo Mendes (org.), $1^{\text {a }}$ edição. São Paulo: Cia. Das Letras, 1996.

ZANINI, Walter. A arte no Brasil nas décadas de 1930-40: O Grupo Santa Helena. São Paulo: Nobel, 1991. 